\title{
EFFECTS OF THE HEAT WAVE TO THE OBJECT SECURITY
}

\author{
J. SZENDI ${ }^{1}$
}

\begin{abstract}
Effects of the heat wave to the object security. The article investigates the optimal usage of the weather forecast reports supporting the man guarding and engineering services located in industrial sites. The science of Meteorology have developed many relationships within heat shock and their location. The heat - especially when it occurs quickly - affects the man guarding services, as their watchfulness sinks. Using professional weather services, the operation commander has the ability to act, so the team can keep up the high service level. Heat and cold affects highly the capability of the guards - especially with age increasing - it might end up accidental death at site. The article is a sample of applied research, as it investigates the followups of the weather forecaster's warnings. As soon as the heat shock is reported by using weather forecasting services, a number of actions should be pulled in, making sure to save the guards and the equipment around the factory. Some essential responses - like to keep more drinking water at site - is just the first step. All clothing and Environment Health and Safety (EHS) related equipment should be reviewed, also all operation commands should be optimized for the changed conditions. The heat affects the blood pressure, the veins and vigilance of the staff. Regular breaks in air conditioned areas should be organized. There is a special case if the guard is a senior person. Seniors are much more affected, so preventive operation orders should be set up when a man guarding contract is won. In most cases, the price is the first during contracts, so the technical content is underestimated to keep the price low. Basically, if the team size is optimized for a normal day operation, the operation team leader might not have enough staff on a very hot or cold day. This issue affects the object safety, as the primary recovery services will not be available in time.
\end{abstract}

Keywords: weather forecast, object security, man guarding services.

\section{INTRODUCTION}

As weather forecast is a proper discipline, its results can be used in engineering and man guarding services to increase the object security. If at a specific location the people can feel the normal expected average temperature like expected in the spring or autumn, the factory has less risk, than during the summer or winter, when the outdoor temperature might be dangerous for

${ }^{1}$ Doctoral School of Military Engineering, 2185 Váckisújfalu, Petőfi u. 27, Hungary, e-mail:

j.szendi@yahoo.com 
humans. Both the cold and the extreme hot weather conditions might cause machine dysfunctions. The speed of the change is also an important parameter as quick change usually puts pressure on the people and the machinery as well. The ambient temperature highly affects the workers, including the man guarding services. As seen in Fig. 1, the weather forecast services reports a heat wave expected within a day in Hungary. The weather reports are widely available, but at sites usually the management is not using the reports as critical data.

In engineering services the parameters are measured. One of the indicators is the Key Production Indicators (KPI) (Rouse, 2016), which is a number used to describe the quality of the service level.

The question is how could the local management use the weather forecasts report, and what actions should be pulled in to prevent Health and Safety (EHS) (available at http://www.hse.gov.uk/aboutus/strategiesandplans /index.htm) related accidents? How can we prevent the fall of the KPI at a midsize food manufacturer plant by using the forecast correctly?

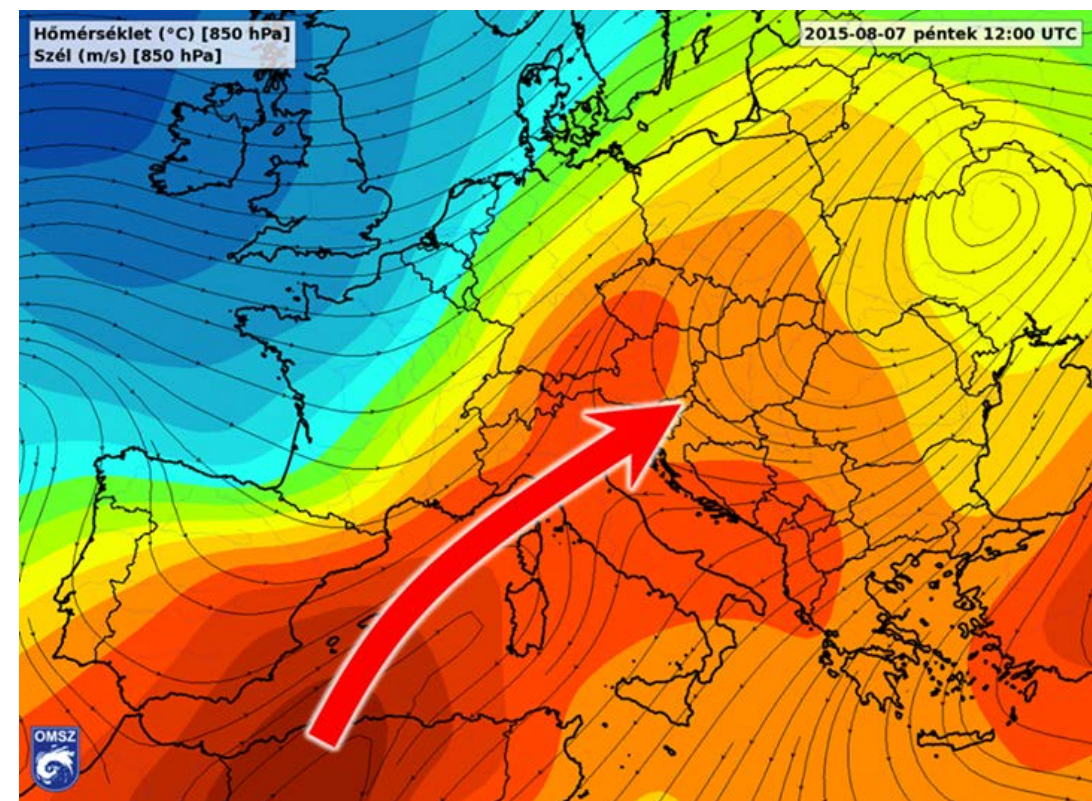

Fig.1. Useful weather forecast. (Source: http://lajk.startlap.hu/2015/07/30/ jon-a-kovetkezo-hohullam-kozel-40-fokkal/)

\section{METHODS OF INVESTIGATION}

The weather forecast models are quite well described theoretically, and they are software supported for practical use (Mika, 2013; Ciaranek, 2016; Lakatos, 2016). The weather forecast stations are linked - as their employers 
communicate - and their forecasts are based on long time experience. The weather forecast is mostly trustable, especially in case of extreme weather conditions. Most heat waves can be forecasted in Europe, in the most cases with few days prior to their occurrence. Sometimes, extreme wind conditions cannot be forecasted so accurate, but usually the forecast includes the phrase "storm might come". Weather forecasters are working for years to develop good models, and even though they might have minor bias, for normal industrial use these models are good enough.

The problem comes if the good forecasts are ignored by higher management in the industry. In Hungary, there was a huge accident during the Celebrates of $20^{\text {th }}$ of August, 2006 (http://index.hu/bulvar/tuzij060820/), when people died because of the weather forecaster's warnings were ignored. The extreme wind blew away the program.

Other forms of precipitation can cause also accidents - like sleety rain what can build up on the rails and electric cables. This build up might end as heavy mass on the cables. The metal becomes more inflexible as temperature decreases and it might fall dawn. This situation happened in Hungary in the middle of 2014 winter (http://index.hu/galeria/index/belfold/2014/12/02/kedden _is_az_onos_esorol_szoltak_a_hirek/) as seen in Figure 2. The area and even the vehicles were hardly effected with ice. Human movement became extremely difficult, and this fact increased the recovery time. Power loss is a clear risk as it ends up losing water supplies also. Unmanaged weather forecast can mess up the availability of the critical infrastructures (Berek and Davidovitz, 2012), which could be prevented by using good action or recovery plans.

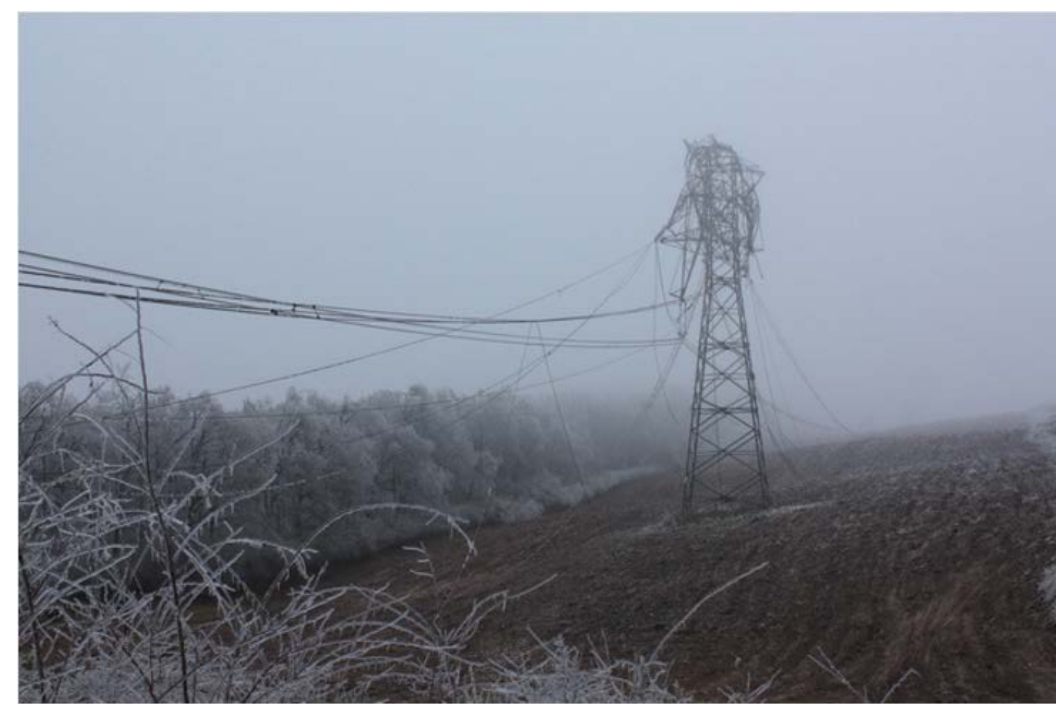

Fig. 2. Ice on the cables. It caused massive power cut in Hungary in 2014 (Source: http://index.hu/galeria/index/belfold/2014/12/02/kedden_is_az_onos_ esorol_szoltak_a_hirek/) 
Both extreme cold and hot temperature might be fatal for the facility services. The too cold weather conditions usually hardens the metals, like rails and electric cables, while too hot weather conditions are bad for the electric connectors which might become loose. A thermo photo of a loose S-phase connector on a high voltage transformer is presented in Figure 3. The picture is made by a thermo resistive camera and it can show the untorqued bolt connection. If the ambient temperature is low, the substation can survive the winter. If it is not maintained around the spring due to a poor maintenace plan or cost saving order it might fail when the ambient temperature rises. When an extreme heat wave occures, the connection becomes extremely hot and the metal in the connection has the lowest melting point and melts down and the equipment fails.

Most factories stop as soon as there is a power cut, as the machinery and the facility services have no power. This is a clear security gap within the object safety. Some of these issues could be prevented by using quality weather forecasts and building the maintenance plans so that they meet the forecasts. In the manufacturing sector, the essential services like cooling, central heating, lighting, boiler houses etc. are affected, and server rooms can overheat. Obviously, in case of power cut the manufactured food can become a waste, so actually ignoring a good weather forecast report might end in profit loss also, especially in case of perishable goods.

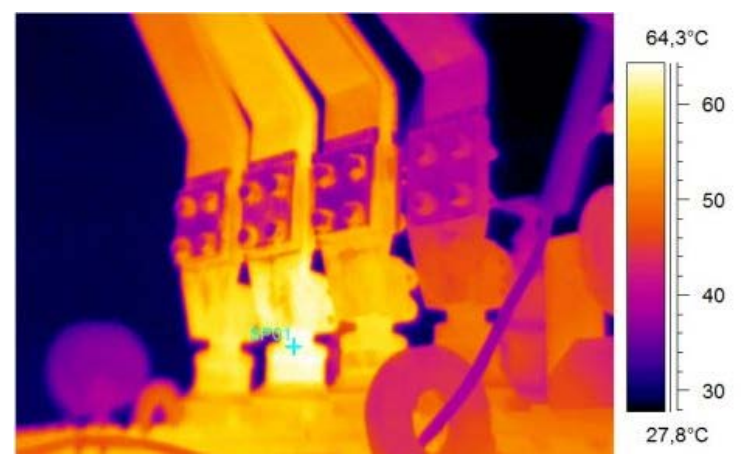

Fig. 3. Un-Torqued connection around the ceramic insulator. $T$ phase connector is about $70^{\circ} \mathrm{C}$ (Source: http://sanicumkft.hupont.hu/2/termografia)

Even electric connections are highly affected, most of the industrial coolers, chillers, heat pumps are also working in much hard conditions during a heat shock. This, in a very hot day, an unmaintained chiller will probably stop, mostly on high pressure alarm.

The method to investigate the roots is to log all in-house breakdown and link the origin of the fault to the root. In this specific situation, the root is human fault. Even when the warning system is available the higher management 
ignores the risks due to the costs. This type of integrity faults can be only estimated and not measured, as this KPI are hidden in most cases by the management to hide their own responsibility.

\section{THE EFFECTS ON WORKERS}

Humans are very sensitive when temperature drops or increases quickly. Human body controls its temperature mostly by sweating and breathing. When the temperature drops quickly, humans become quite unmotivated to go outside. In case of man guarding services it is a safety gap in the object security. The risk of attack on the site is also less, as the robbers and the thieves are also not motivated to action in very bad weather conditions. But in special cases, the thief takes advantage of this condition. Some specialized intruders might use the weather forecasts, as during heavy rain, sleety rain or very hot days and they can use the security gap. In bad weather conditions the clues might be washed out, so basically the thief has advance.

\section{RISK ANALYSIS USING THE WEATHER FORECAST}

Even in engineering services and in man guarding services, the response for any issue should be planned and controlled. One of the methods is to set up a risk analysis to estimate the risk and choose priorities. A sample assessment is shown in Table 1. The risk assessment contains the actions that should be done instantly to prevent accidents or additional costs.

Table 1. Sample of the risk assessment

\begin{tabular}{|l|c|c|c|c|c|c|}
\hline \multirow{2}{*}{$\begin{array}{c}\text { Seriousness of the } \\
\text { consequences }\end{array}$} & \multicolumn{5}{|c|}{ Probability of accident } \\
\cline { 2 - 7 } & F. Impossible & E. Unrealistic & D. Marginal & C. Occassional & B. Probable & A. Frequent \\
\hline I. Cathastrophic & & & 3. & & & \\
\hline II. Critical & & & & & & 1. \\
\hline III. Major & & & & & & \\
\hline IV: Negligable & & 2. & Preferred & & & \\
\hline
\end{tabular}

Samples of risks:

\begin{tabular}{|lll|}
\hline & Problem: & Solution: \\
1. & Overheated chiller at spring. & Carry out preventive maintenance \\
2. & $30 \mathrm{~cm}$ snow in August & Not realistic issue \\
3. & Death at site due to dehydration & Reviewing all site rules \\
\hline
\end{tabular}

Icy pavement is a huge risk, due to the fact that it is very slippy. Keeping salt and tools nearby is a good preventive action, but the staff should be trained at the same time to use them in a regular basis to make the site safety. When the weather forecast report informs about snowfall, additional workers should be called in to clear build ups from the roofs. 
A very hot day is risky for cooling machinery and for sensitive people (due to the blood pressure problems and dehydration), as well as for all electric and IT services. In order to prevent the danger, the risk assessment should be followed by an action plan. Prior to any heat shock, all facility services should be maintained as a preventive action. If the maintenance had not been carried out in the spring by some reasons (absence of the Engineering Manager, new FM supplier etc.), a casual short maintenance is still a better solution, than waiting for the bad weather unprepared.

\section{PRIMARY ACTIONS AFTER FORECAST REPORT RECEIVED}

When the weather forecast report contains a heat wave, storm, sleety rain, or any other dangerous phenomenon, the local commander should act instantly to save the premises and the people at site. The actions are more than likely common sense, but if they are ignored, the risk of EHS related accidents will increase, especially if the guard is a senior person. The following primary actions should be taken prior to the bad weather condition occurrence:

1. review the guarding instructions;

2. review the recommended clothing;

3. review the allowed breaks;

4. supply cold water source or hot tea;

5. supply cold area or use one air conditioned room as restroom;

6. order shorter shifts;

7. signing of holidays for senior guards.

Secondary actions exist to prevent security loss for the client. As an example, we investigate the uniform rule to prevent repetition. In the most cases, the guards are ordered to wear full uniform to meet client's standards. In fact, long trousers act as an insulator on the legs and makes uncomfortable the guard's movement. Basically, wearing hot uniform is a weak point in the object security on a very hot day, as the clothing overheats the body and the guard cannot act as quick as on a normal day.

Very often the client expects the full uniform, as it meets their expectations regarding the dress code. In case of man guarding services, the added value is not really the look, rather the site safety and the object security. As a secondary action, the dress codes should be reviewed and optimized, allowing to reach a higher object security. If the client states that the long type of uniform is essential at site, the restroom area must be air conditioned or more frequent breaks must be allowed by the action plan.

Long time solution might come from the new EHS regulations. The dress code should allow short cloths. In summer time, we can see policeman in shorts, especially in areas where the tourists are on holiday. In Australia shorts with a tie is a common uniform in offices, as the comfort is more important for 
the people. In Europe we have to wait until the company changes the dress code.

\section{FUTURE RESPONSE FOR THE SAME PROBLEM}

Any weather conditions should arrive, better personal protective equipment (PPE) can eliminate some of the impact. There are polymer materials, which can act as very good insulator (POLAR). They might contain moisture control properties allowing to control the body temperature. Nowadays, to compensate very cold ambient temperature, heated clothing can be used. For emergency services many special equipment have already been developed, allowing to recover body heat after accidents. One of the most appropriate solutions is a special glove, which can take out heat or deliver heat to the hands. Human body - using the blood flow - can transfer the heat, and the injured person can survive the shock.

The future clothing might use special sources of heat. One of them is chemical energy, when chemical reaction makes the heat. Other solutions might be an electric one: in this case, electric energy is used for recovery. The limit of the technology is still the weight of the batteries; they are still too heavy. In the future, when special sources will exist, the recovery time will be shorter. As an example, isotope batteries might be very useful in the future, especially in very cold areas or after accidents.

Using special elements like Peltier cells, some future uniforms can cool the body by increasing the outside temperature. In this case the electrical energy is used to heat the outside surface, which takes out heat form the skin. Even though this type of clothing seems to be future, nowadays heated boots are used for woodcutters, as the chainsaw can generate power for the heating elements.

\section{CONCLUSION}

"The commander or leader should be able to estimate impediment factors, when his staff wears the equipment. In connection, it is a requirement for the commander to be able to estimate the consequences for personnel exposed to heat stress for a longer period of time. He should know the countermeasures to ease the reductive effects of uniform for capabilities and personal comfort” (Beret, 2013).

Weather forecasts are well developed and their data should be used in engineering and man guarding services. The response of the extreme weather can be estimated, and all EHS regulations should be followed for the safe operation. In the future, special clothing can reduce the risk of accidents, as the person in charge gets much smaller impact of ambient temperature. One of the 
methods to eliminate accidents is to carry out a method statement and risk assessment prior to any engineering or man guarding task.

\section{REFERENCES}

1. Berek, T., Davidovitz, Z. (2012), Vízbiztonsági terv az ivóvízellátás minöségirányitási rendszerében Hadmérnök. http://hadmernok.hu/2012_3_

2. Beret, T. (2013), Key elements of standards of proficiency for CBRN defence in military officers' education, Hadmérnök VIII(4) szám - 2013. December 33-39.

3. Ciaranek, D. (2016), Short-Term Changes of Air Temperature in Poland. Air and Water- Components of the Environment, 210-216. davidovits_berek1.pdf

4. Lakatos, L. (2016), The Role of Water in Microclimate Manipulation in Orhards. Air and Water- Components of the Environment, 416-423.

5. Mika, J. (2013), Meteorological Extremes and Their Changes: Phenomenology and Empirical Aproaches. Climatic Change 121: (1), 15-26.

6. Rouse, M. (2016), Key performance indicator. Available at: http://searchcrm. techtarget.com/definition/key-performance-indicator.

7. http://sanicumkft.hupont.hu/2/termografia

8. http://www.hadmernok.hu/134_04_berekt.pdf

9. http://lajk.startlap.hu/2015/07/30/jon-a-kovetkezo-hohullam-kozel-40-fokkal/

10. http://www.hse.gov.uk/aboutus/strategiesandplans/index.htm

11. http://index.hu/bulvar/tuzij060820/

12. http://index.hu/galeria/index/belfold/2014/12/02/kedden_is_az_onos_esorol_szo ltak_a_hirek/ 